dried forms a very tough coat for the cyst. In the case of Stylocephalus giganteus it seems that the physiological character which makes the cyst resistant to desiccation, even though dehydration proceed to the distortion of the cyst, is of value to this species in much the same way as the protective envelopes of the first two species. The host of Stylocephalus giganteus is active throughout the winter on warm days, so that this species does not have to overcome the loss of host during the winter months as does Gregarina rigida in the grasshopper, and Eleodes sp. have been taken in December and January containing as many gregarines as beetles of the same species taken in August. These beetles are however dis-

\section{SEMI-PERMEABLE CAPSULES}

During a series of experiments to determine the permanency of the fermentative reactions of intestinal bacteria in stored waters, it became necessary to use semi-permeable capsules. A review of the literature failed to show any method which was suitable for our purpose.

As in McCrae's work, gelatine capsules (size 00) are used as a basis for the colloidin capsule. A glass tube about $15 \mathrm{~cm}$. in length is warmed in the gas flame and pressed into the closed end of the empty gelatine capsule. The gelatine plug which inevitably forms in the glass tube must be removed, at this point by means of a wire, otherwise ruptures are

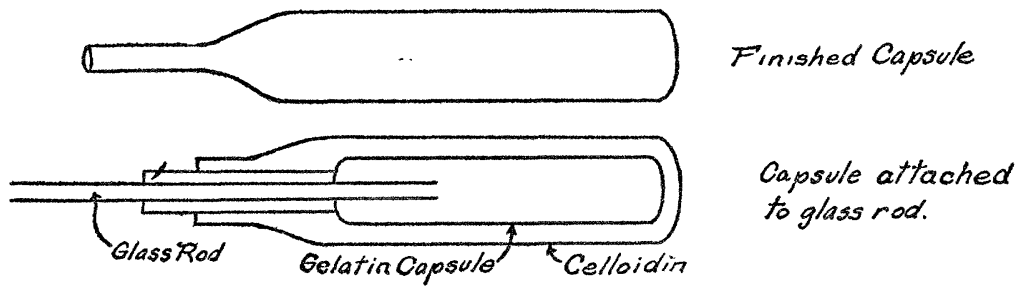

FIG. 1.

tributed through a semi-arid region and the favorite habitats of Eleodes spp., under stones or at the bases of shrubby plains plants, are quite dry for the greater part of the year, subjecting the cysts of Stylocephalus giganteus even though protected to some extent by the excrement of the host, to considerable drying. As shown by the cysts under observation. moisture is essential to the completion of sporocyst formation, since the cysts kept in dry air did not reach the gray and black stages until after they were placed in water. By examination of the meteorological data for eastern Colorado it may be seen that the period of drying to which the cysts here considered were subjected, over four months, exceeds the average droughts in this part of the plains where Eleodes spp. are so extensively parasitized.

\section{UNIVERSITY OF COLORADO}

liable to occur when the capsules are boiled later.

The union of the capsule and the glass rod is made airtight by coating the union with a twenty per cent. solution of gelatine by means of a small brush. The layer of gelatine is extended up the glass tube for a distance of about $4 \mathrm{~cm}$. If the two halves of the capsule do not fit tightly, it is advisable to paint them also with the gelatine.

After thoroughly drying, the capsule is dipped into the colloidin solution (colloidin 1 part, ether $1 \frac{1}{2}$ parts and alcohol $1 \frac{1}{2}$ ) until a proper thickness is attained, which may be judged by holding the capsule before the light. Experience has shown that at least four dippings are necessary. It was found that the finished capsules were often weak at the point where the halves of the gelatine capsule meet. This point was strengthened by allowing additional colloidin to collect at this place. The 
dipped capsules are allowed to dry over night. Premature boiling causes the capsules to swell and burst due to the presence of ether and alcohol in the inner layers of the colloidin. They should not be boiled until they are odorless.

The colloidin capsules are removed from the glass rods by immersing them in boiling water for ten minutes using the glass rods to control the capsules. Leaks may be detected by blowing through the glass rods. If no leaks are detected the capsules can be easily removed from the glass when the gelatin has melted. The capsules generally contain gelatine which may be objectionable in some experiments. This may be removed by filling the capsules with water and boiling them briskly for one half hour. If any of the gelatin remains, the process must be repeated until all has been removed.

The finished capsules may be filled with bouillon, water or any liquid media and sterilized by intermittent sterilization, after which they may be inoculated by platinum needle, pipette or hypodermic syringe. Sealing is accomplished by placing a drop of thick colloidon in the neck of the capsule and allowing it to harden. Leaks may be detected by washing the capsule with sterilized water, after which it is dropped into a tube of sterilized broth and incubated twenty-four hours.

\section{William W. Browne, David Soletsisy}

The College of the City of New York

\section{SOCIETIES AND ACADEMIES}

THE WISCONSIN ACADEMY OF SCIENCES, ARTS AND LETTERS

THE academy in conjunction with the Wisconsin Archeological Society, the Wisconsin Audubon Society, the Madison Mycological Society, the Wisconsin Mycological Society and the Wisconsin Natural History Society, held its forty-fourth annual meeting at Milwaukee in the Public $\mathrm{Mu}$ seum, when the following program was presented:

First Session Thursday, April 9, at $90^{\prime}$ 'clock

"Some Problems Involved in the Cultivation of Medicinal Plants," by Edward Kremers.

"The Garden City Movement in England and Germany,' by L. S. Smith. (Illustrated.)
"The Significance of Highway Maintenance in the United States," by L. S. Smith. (By title.)

"A New Indicator for Acids and Alkalis," by A. F. Gilman.

"'Origin of the Republican Party," by A. F. Gilman.

"Some Variations Noted in Gall Stones," by G. A. Talbert.

"Geologic Occurrence of Radium Ores," by Rufus Mather Bagg. (Illustrated.)

"The Relation of the Corpus Christi Procession to the Corpus Christi Play in England,"' by Merle Pierson.

"Some Versions of English Ballads Collected in Milton,', by Mabel Maxson.

"William Gager and the Academic Drama at Oxford,' by Karl Young. (By title.)

The second session was held on the evening of Thursday, April 9, at 7:30 o'clock, when Professor S. W. Williston, of the University of Chicago, delivered a lecture on "Early Land Animals of North America." This lecture was fully illustrated by many restorations of early extinct animals for the most part made by the lecturer. The lecture was well attended by the public, and was most interesting and valuable.

Third Session, Friday, April 10, at 9:30 o'clock

"The Climate of Madison, Wis. 1. A discussion of the observations of temperature, 1869 to 1913 ,', by Eric R. Miller.

"The Approach to Popular Literature," by Arthur Beatty.

"A Method for Determining Approximate Metabolic Demands of Plants for Soil Water,' by $\mathrm{H}$. E. Pulling. (By title.)

"Physiological Changes Causing Black Heart in Potato Tubers," by E. T. Bartholomew. (By title.)

"Further Studies on Wisconsin Tremellineæ,", by E. M. Gilbert. (By title.)

"Successful Method for Growing Clitocybe illudens and Armillaria mellea,"' by V. H. Young. (By title.)

"The Effect of Lateral Pressure on the Formation and Direction of Growth of Plant Organs,' by J. B. Overton. (By title.)

"The Development of Botanical Microtechnique,', by Gilbert M. Smith. (By title.)

"The Reaction of Pigment Cells in the Trout to Chemical Stimuli," by John M. Loshinski.

"Fertilization in the Parasitic Copepoda, Ler. ncoopoda Edwardsii Olsson," by Nathan Fasten.

"Mutation and Atavism in Plants," by How. land Russell.

"Heat Budgets of European and American Lakes,' by E. A. Birge.

"Physiological Age as Determined by Growth of Epiphasis of Wrist Bones," by A. H. Yoder.

"On Habits and Relationship of Some Muscoid Flies," by Sigmund Graenicher.

"Field Record of the Wisconsin Mycological Society for the Season of 1913,"' by Dr. Lewis Sherman. 